\title{
Compartmentation of Terpenoid Biosynthesis in Green Plants
}

\author{
A PROPOSED ROUTE OF ACETYL-COENZYME A SYNTHESIS IN MAIZE CHLOROPLASTS
}

\author{
By S. P. J. SHAH AND L. J. ROGERS \\ Department of Biochemistry and Agricultural Biochemistry, University College of Wales, Aberystwyth
}

(Received 10 March 1969)

\begin{abstract}
On the basis of radioisotope-incorporation experiments it is suggested that acetyl-CoA, an obligatory intermediate in chloroplast terpenoid biosynthesis, may be formed in maize from photosynthetically fixed carbon dioxide by the route carbon dioxide $\rightarrow$ glycollate $\rightarrow$ glyoxylate $\rightarrow$ glycine $\rightarrow$ serine $\rightarrow$ pyruvate $\rightarrow$ acetyl-CoA. The proposed route is supported by conventional radioisotope-dilution studies and by experiments with inhibitors affecting reactions involved in the pathway. The proposed route appears to play little part in formation of extrachloroplastidic sterol.
\end{abstract}

It seems clear that most if not all terpenoids found in the chloroplast are synthesized in situ (see, e.g., Treharne, Mercer \& Goodwin, 1966), a process that requires the generation from carbon dioxide of considerable amounts of acetyl-CoA. The present studies are concerned with an investigation into the metabolic route by which the synthesis of acetyl-CoA might occur.

A preliminary survey of the literature for possible intermediates between carbon dioxide and acetylCoA revealed the importance of glycollic acid and glyoxylic acid in the metabolism of photosynthetic organisms. Under certain conditions nearly $50 \%$ of the carbon atoms fixed during photosynthesis may pass through glycollic acid (Zelitch, 1959; Tolbert, 1963). Comparatively little is known, however, about the route of glycollate formation from carbon dioxide or about the possible metabolic fate of the glycollic acid formed during photosynthesis. Hess \& Tolbert (1966a) suggested that glycollate arises from components of the photosynthetic carbon cycle, since in carbon dioxidefixation studies the specific activity of phosphoglyceric acid was greater than that of glycollic acid. This view is supported by Orth, Tolbert \& Jiminez (1966). However, Zelitch (1965a) suggested that glycollate arises from a previously undetected carbon dioxide-fixation pathway involving reduction of carbon dioxide and condensation of $\mathrm{C}_{1}$ units, and Tanner, Brown, Eyster \& Treharne (1960) suggest that glycollate arises from condensation of two molecules of carbon dioxide. From studies of $\left.{ }^{14} \mathrm{C}\right]$ glycollate metabolism and photosynthetic ${ }^{14} \mathrm{CO}_{2}$ reduction Chan \& Bassham (1967) have concluded that glycollate does not arise from an intermediate in the primary pathways of photosynthetic fixation of carbon dioxide.
The possibility that glycollic acid or a metabolically derived compound might be a precursor of chloroplastidic acetyl-CoA was therefore investigated. Preliminary results (Shah, Rogers \& Goodwin, 1967a) showed glyoxylic acid to be an effective precursor of chloroplast terpenoids and further studies were guided by likely metabolic routes (Scheme 1) for formation of acetyl-CoA from glycollic acid and glyoxylic acid. Special attention was paid to the route involving the pathway glycollate $\rightarrow$ glyoxylate $\rightarrow$ glycine $\rightarrow$ serine since constituent reactions of the conversion of glycollate into serine by this sequence have been established in the leaf by many workers (Krupka \& Towers, 1959; Rabson, Tolbert \& Kearney, 1962; Wang \& Waygood, 1962; Zelitch, 1959, 1964; Tolbert, 1963; Sinha \& Cossins, 1965; Asada, Saito, Kitoh \& Kasai, 1965; Hess \& Tolbert, 1966b).

The possible incorporation of some of these intermediates into terpenoids is suggested by data reported by a number of workers. Thus Shetty \& Miller (1966) have shown some incorporation of glycine into carotenes in tobacco leaves, and glycine is also incorporated into lipid by chloroplasts (Smirnov \& Rodionov, 1964) and by carrot root tissue (Sinha \& Cossins, 1964). The $\alpha$-carbon atom of glycine is effectively incorporated into the phytol side chain of chlorophyll in wheat leaves, whereas the carboxyl carbon atom of glycine and both carbon atoms of acetate are not readily incorporated (Roberts \& Perkins, 1966). These authors concluded, somewhat prematurely, that phytol may be synthesized by a novel route not involving acetate and mevalonic acid. The incorporation of the $\alpha$-carbon atom of glycine into $\beta$-carotene occurs in Phycomyces blakesleeanus (Mackinney, Chichester, Nakayama \& Goodwin, 1955), whereas 


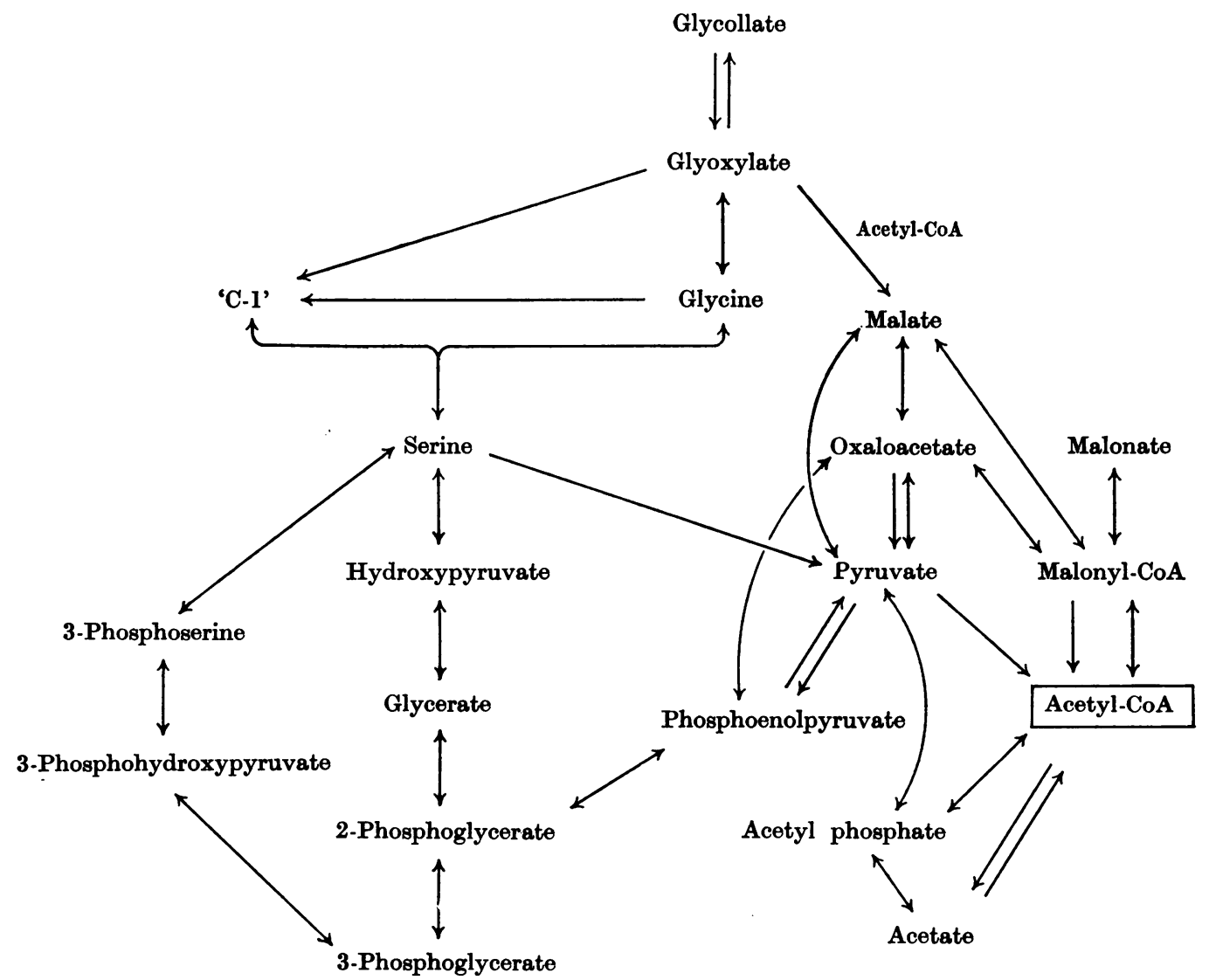

Scheme 1. Possible routes of formation of acetyl-CoA from glycollic acid. To simplify the Scheme two routes identified in micro-organisms, by which glyoxylate is transformed through erythro- $\beta$-hydroxyaspartate and tartronic semialdehyde into oxaloacetate and glycerate respectively, have been omitted.

the carboxyl carbon atom is released as carbon dioxide. However, the latter conversion is not associated with any photosynthetic process.

At the enzymic level it is known that glycollate oxidase and glycollate reductase occur in plants (Delavan \& Benson, 1959; Kearney \& Tolbert, 1962; Rabson et al. 1962; Zelitch, 1965b; Chan \& Bassham, 1967; Thompson \& Whittingham, 1968). Plant tissues also contain serine hydroxymethyltransferase, the enzyme that catalyses interconversion of glycine and serine (Wilkinson \& Davies, 1958; Hauschild, 1959; Cossins \& Sinha, 1966; Prather \& Sisler, 1966; Mazelis \& Liu, 1967) and formyltetrahydrofolate synthetase, which catalyses formation of $N^{5} N^{10}$-methylenetetrahydrofolate, an essential cofactor for glycineserine interconversion (Hiatt, 1965 ; Iwai, Susuki \& Mizoguchi, 1967).

The experimental approach used in the present investigations was to assay in vivo chloroplastidic
acetyl-CoA synthesis by measuring the incorporation of radioactive metabolites into $\beta$-carotene. Since the incorporation of precursors into sterol (extrachloroplastidic) was also measured this gave the opportunity, not otherwise possible with a study in vivo, of distinguishing between formation of acetyl-CoA inside and outside the chloroplast. It is known (Stumpf, Brooks, Galliard, Hawke \& Simoni, 1967) that the chloroplast bounding membrane is relatively impermeable to acetyl-CoA.

In our studies the possibility of a compound being a precursor of chloroplast terpenoids was therefore examined by administration of trace amounts of the radioactive compound during greening of excised etiolated maize seedlings and subsequent isolation and radioassay of the $\beta$ carotene from the green leaves. Incorporation of the precursor into extrachloroplastidic sterol was estimated by isolation and radioassay of a sterol fraction from the same tissue. Preliminary reports 
of these studies have appeared (Rogers, Shah \& Goodwin, 1967; Shah, Rogers \& Goodwin, $1967 a, b, 1968)$.

\section{EXPERIMENTAL}

\section{Radiochemicals}

All radiochemicals were purchased from The Radiochemical Centre, Amersham, Bucks., with the exception of [2-14 C]glycollic acid, which was supplied by Isotopes Inc., Westwood, N.J., U.S.A. The specific radioactivities of the radioactive substrates used in the investigations were: [1.14C]glycine, $5 \cdot 2 \mu \mathrm{c} / \mu$ mole; [2.14C]glycine, $21 \mu \mathrm{c} / \mu$ mole; [2-14 C]glycollic acid, 9.5 $\mu \mathrm{C} / \mu$ mole; DL-[2-14C]mevalonic acid, $5 \cdot 8 \mu \mathrm{c} / \mu$ mole; $\mathrm{L}$-[U-14C]serine, $6 \cdot 4 \mu \mathrm{c} / \mu$ mole; sodium [2-14 C]acetate, $1.5 \mu \mathrm{c} / \mu$ mole; sodium [1-14 C]glyoxylate, $5 \cdot 1 \mu \mathrm{c} / \mu$ mole; sodium $[2-14 \mathrm{C}]$ glyoxylate, $4 \mu \mathrm{c} / \mu$ mole; sodium $\left[1 .{ }^{14} \mathrm{C}\right]$ malonate, $4 \cdot 7 \mu \mathrm{c} / \mu$ mole; sodium $[2.14 \mathrm{C}]$ malonate, $12 \cdot 1 \mu \mathrm{c} / \mu$ mole; sodium $\left[2-{ }^{14} \mathrm{C}\right]$ pyruvate, $10 \cdot 2 \mu \mathrm{C} /$ $\mu$ mole; sodium $\left[{ }^{14} \mathrm{C}\right]$ formate, $1 \cdot 4 \mu \mathrm{c} / \mu$ mole.

\section{Biological methods}

Biological material. Zea mays (var. Rhodesian White Tooth Double Hybrid) seeds were purchased from Gunsons (Seeds) Ltd., London E.1.

Cultivation of seedlings. Etiolated 6- or 7-day-old seedlings, germinated in vermiculite, were used for all experiments.

Exposure of etiolated seedlings to ${ }^{14} \mathrm{C}$-labelled substrates. Excised shoots were used for all the experiments described to obviate any difficulties of uptake of certain substrates through the root system of the seedlings.

The shoots after excision and presentation of the substrate were exposed to continuous illumination for the succeeding $24 \mathrm{hr}$. The illumination of such etiolated seedlings results in a rapid synthesis of $\beta$-carotene and chlorophyll within the first 24-48 hr. (Kay \& Phinney, 1956; Goodwin, 1958). The weight of shoots taken (usually 15-20 shoots) and the radioactivity administered are given in the text.

(a) Radioisotopes other than ${ }^{14} \mathrm{CO}_{2}$. Etiolated shoots were excised at the node and the excised ends immersed in a shallow glass beaker containing the radioisotope in water to a depth of $2 \mathrm{~cm}$. The shoots were then exposed to continuous illumination by means of a Phillips Cold Light $(250 \mathrm{w})$ for the experimental period. To encourage transpiration from the leaf surface, and thus facilitate uptake of the substrate, the shoots were kept in a continuous air stream, created by a small electric fan placed a few feet away. Within $3 \mathrm{hr}$. of illumination the formation of chlorophyll in the shoots was apparent to the naked eye.

(b) ${ }^{14} \mathrm{CO}_{2} .{ }^{14} \mathrm{CO}_{2}$-incorporation experiments were carried out in an apparatus similar to that described by Treharne et al. (1966). Radioactive gas was generated by the addition of lactic acid to $\mathrm{Ba}^{14} \mathrm{CO}_{3}$. At the end of the experimental period a continuous stream of $\mathrm{N}_{2}$ was passed through the apparatus to remove unfixed ${ }^{14} \mathrm{CO}_{2}$. Illumination was provided by means of a Phillips Cold Light (250 w) placed $1 \mathrm{ft}$. above the lid of the incubation chamber.

\section{Analytical methods}

Extraction and separation of terpenoids. The tissues were weighed and then cut into small pieces and extracted with acetone $(50 \mathrm{ml} . / 10 \mathrm{~g}$. of seedlings) in an Ultra-Turrax homogenizer (Hudes Merchandising Co. Ltd., London W.1) for 60 sec.; the acetone was filtered off and the residue was re-extracted. The procedure was repeated until the final extract was colourless (usually three or four extractions were required). An equal volume of water was added to the combined acetone extracts and the mixture exhaustively extracted three or four times with redistilled diethyl ether (50 ml. portions). The combined ether extracts were freed from acetone with water and then dried over anhydrous $\mathrm{Na}_{2} \mathrm{SO}_{4}\left(20 \mathrm{~g}\right.$. $/ 100 \mathrm{ml}$. of extract) for $30 \mathrm{~min}$. The $\mathrm{Na}_{2} \mathrm{SO}_{4}$ was filtered off and washed with diethyl ether; the ethereal extract was evaporated to small volume at $30^{\circ}$ under reduced pressure in a rotary evaporator, and quantitatively transferred to a small conical flask (25 ml.). Any residual water was removed by adding a few millilitres of ethanol and evaporating to dryness under $\mathrm{N}_{2}$. During all extractions the vessel containing the lipid was enclosed in tin-foil to minimize photodecomposition of pigments. The dry lipid was weighed and then made to known volume for radioassay and occasionally for determination of chlorophyll.

Saponification and extraction of unsaponified matter. The method of Goodwin (1955) was used except that saponification was carried out at room temperature overnight and not with heating.

Separation of terpenoids. The unsaponifiable components were first separated into crude fractions by column chromatography on alumina (Brockmann grade 3) supports (10g. of adsorbent/100 mg. of unsaponifiable components). Before terpenoid separation columns were flushed with purified light petroleum (b.p. $40-60^{\circ}$ ) to remove impurities. Elution was carried out by stepwise fractionation with light petroleum containing increasing amounts of diethyl ether $(100 \mathrm{ml}$. of developing solvent $/ 10 \mathrm{~g}$. of adsorbent); details are given in Scheme 2 , where the terpenoid constituents of each fraction are indicated. The crude $\beta$ carotene and sterol fractions were then purified further by column-chromatographic and t.l.c. techniques.

The carotene fraction was concentrated and passed through a chromatographic column of $\mathrm{MgO}$-Celite 545 $(5: 2, w / w)$ to separate $\beta$-carotene from $\alpha$-carotene, phytoene, phytofluene and squalene. Light petroleum with increasing amounts of acetone was used for the development of the column. The $\beta$-carotene fraction was evaporated to dryness and the pigment dissolved in a small volume of cyclohexane before application to a t.l.c. plate (Kieselgel G; E. Merck A.-G., Darmstadt, Germany). Benzene-light petroleum (b.p. $\left.40-60^{\circ}\right)(1: 19, v / v)$ was used for development of the chromatogram. The $\beta$-carotene zone $\left(R_{F} 0 \cdot 6\right)$, which ran with and did not separate from authentic $\beta$-carotene, was eluted, evaporated to dryness and the pigment dissolved in a known volume of light petroleum. The $E_{450}$ value of the solution was measured with a Unicam SP. 500 spectrophotometer and the amount of pigment present was calculated from $E_{1 \mathrm{~cm}}^{1 \%} 2505$. The visible spectrum of the $\beta$-carotene fraction obtained in this way and determined on a SP. 800 spectrophotometer showed absorption maxima at positions identical with those of $\beta$-carotene, i.e. $\lambda_{\max }$. $(425), 451$ and $482 \mathrm{~nm}$. In cases where the $\beta$-carotene content of the tissue was visibly low the separation on a $\mathrm{MgO}$ column was omitted in favour of a second t.l.c. separation.

$\beta$-Carotene was crystallized by the method of Goodwin (1958). The crystals were washed with ice-cold methanol and, when radioactive, recrystallized to constant specific 


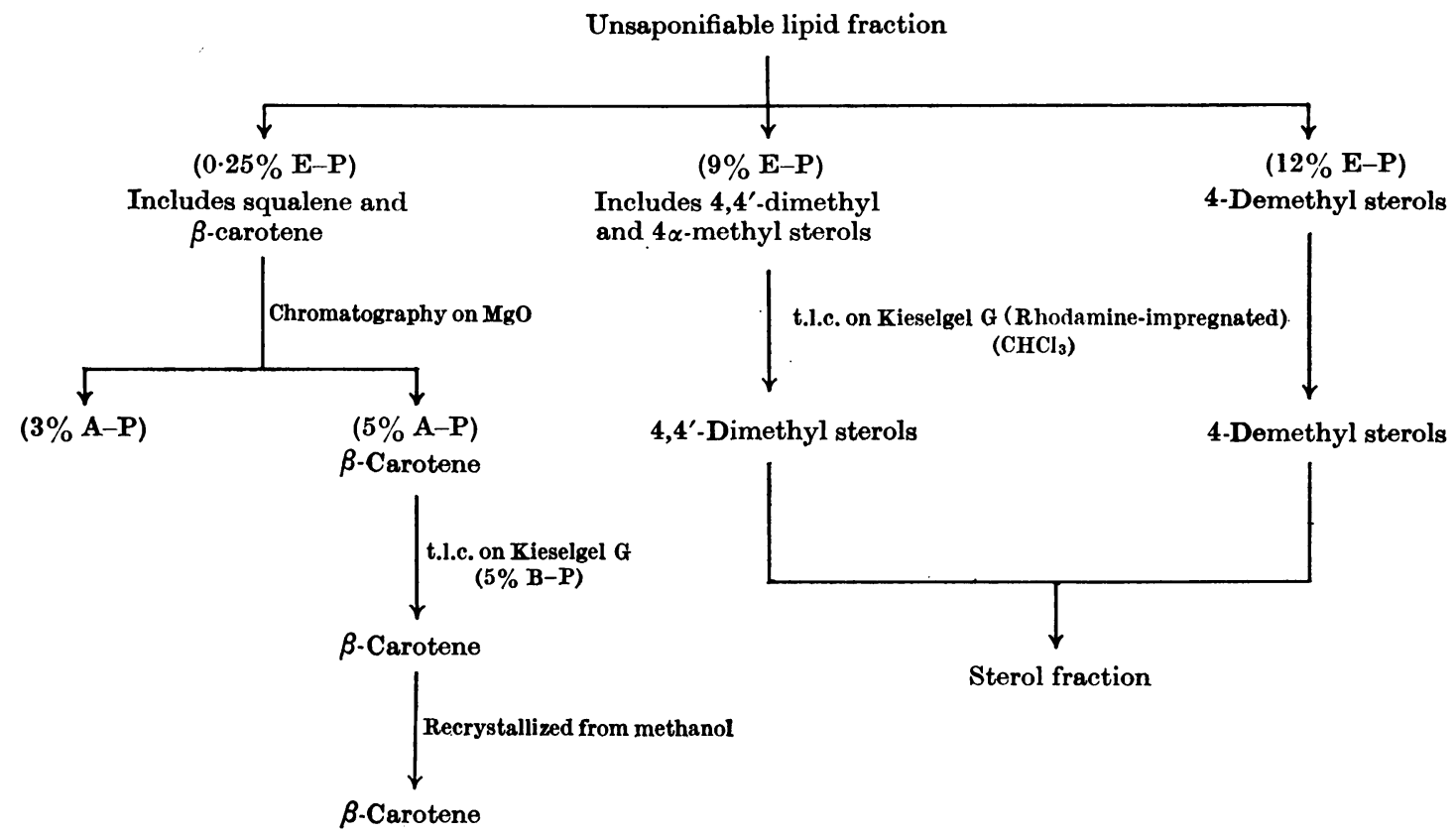

Scheme 2. Separation of the unsaponifiable matter from seedlings. E-P, diethyl ether-light petroleum (\%, $\mathbf{v} / \mathrm{v}) ; \mathrm{A}-\mathrm{P}$, acetone-light petroleum $(\%, \mathrm{v} / \mathrm{v}) ; \mathrm{B}-\mathrm{P}$, benzene-light petroleum $(\%, \mathrm{v} / \mathrm{v})$.

radioactivity. In practice it was found that the specific radioactivity of the $\beta$-carotene was often significantly lowered by the first recrystallization but thereafter usually remained constant after the second and subsequent recrystallizations.

When the amount of $\beta$-carotene to be recrystallized was small it was supplemented by excess of previously purified unlabelled $\beta$-carotene. This facilitated recrystallization of the radioactive $\beta$-carotene recovered from the t.l.c. separation.

Isolation and estimation of $a$ sterol fraction. The $3 \beta$ hydroxy sterols were eluted from the alumina column during the preliminary chromatography of leaf extracts by $9 \%$ and $12 \%$ ether-light petroleum. The 9\% ether-light petroleum fraction contained the bulk of the 4,4-dimethyl and $4 \alpha$-methyl sterols and the $12 \%$ ether-light petroleum fraction contained the main $3 \beta$-hydroxy sterols in maize, $\beta$-sitosterol, stigmasterol and campesterol (4-demethyl sterols). Each fraction was further separated by t.l.c. on Kieselgel G impregnated with Rhodamine $6 \mathrm{G}$ into $4,4^{\prime}$ dimethyl, $4 \alpha$-methyl and 4-demethyl sterols. After developing with chloroform the zones of sterol corresponding to authentic markers of 4-demethyl sterol ( $\beta$-sitosterol and stigmasterol) and 4,4'-dimethyl sterol (lanosterol) were visible under u.v. light (Hanovia Chromatolite lamp) as red spots against a yellow background. The zones corresponding to these two groups of sterols were recovered from the thin-layer plate by elution with diethyl ether, bulked, evaporated to dryness and finally weighed before radioassay.

Quantitative estimation of chlorophyll. Chlorophyll was determined as chlorophyll $(a+b)$ by the method of Arnon (1949).
Radioassay. Samples were assayed in a Packard Tri-Carb model 314 EX Liquid Scintillation Spectrometer. Samples were dissolved in $10 \mathrm{ml}$. of scintillator containing $5.0 \mathrm{~g}$. of 2,5-diphenyloxazole and $0 \cdot 3 \mathrm{~g}$. of 1,4-bis-(4-methyl-5phenyloxazol-2-yl)benzene/l. of toluene. Coloured samples were dissolved in $0.5 \mathrm{ml}$. of toluene in the counting vial and decolorized under u.v. light (Phillips 300 w u.v. lamp) before addition of scintillator solution. All counts were corrected for background and machine efficiency.

Solvents. Light petroleum (b.p. $40-60^{\circ}$ ), benzene (A.R.) and diethyl ether (A.R.) were dried over sodium wire and redistilled; the diethyl ether was distilled over reduced iron immediately before use.

\section{RESULTS AND DISCUSSION}

Preliminary studies showed both glyoxylate and serine to be effectively incorporated into chloroplast terpenoids in greening leaves. The $\beta$-carotene isolated after administration of $[2-14 \mathrm{C}]$ glyoxylate and $\left[\mathrm{U}-{ }^{14} \mathrm{C}\right]$ serine during greening of excised etiolated maize seedlings had high specific radioactivity whereas the specific radioactivity of the sterol fraction was substantially lower. The results obtained with a number of compounds metabolically related to glycollate are shown in Table 1. The absolute values of specific activity have no great significance because of the differences in pool sizes and turnover rates. It is the relative specific activities of the intra- and extra-plastidic terpen- 


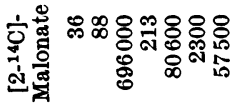

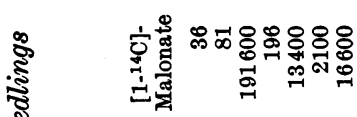

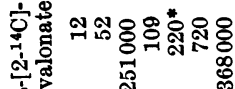
A

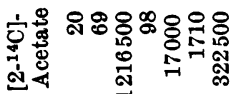

它壱

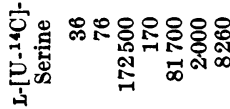

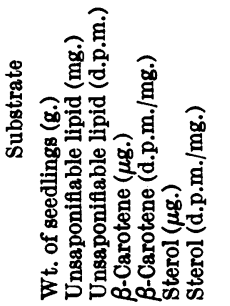

oids in the presence of different labelled substrates that are significant in the present context.

From these experiments we find, as expected from the known relative impermeability of the chloroplast membrane to mevalonic acid, that [2-14C]mevalonic acid is substantially incorporated into sterols but not significantly into $\beta$-carotene. Radioactivity from [2-14C]glycollate, [2-14 C]-glyoxylate, $\left[{ }^{2-14} \mathrm{C}\right]$ glycine and [U-14C]serine, on the other hand, is effectively incorporated into $\beta$ carotene but only to a limited extent into sterols. Similarly, incorporation of radioactivity from [2-14C]glyoxylate into plastoquinone, tocopherol and tocopherol quinones (chloroplastidic) is significantly higher than into ubiquinone (extrachloroplastidic) (O. A. Dada \& D. R. Threlfall, unpublished observations).

The incorporation of radioactivity from [2-14C]glyoxylate and $\left[2-{ }^{14} \mathrm{C}\right]$ glycine into $\beta$-carotene is predictable from the possible routes of conversion of glyoxylate into acetyl-CoA via glycine and serine (Scheme 3). Incorporation of glycine into $\beta$-carotene is slightly lower than expected from consideration of the glyoxylate and serine incorporations perhaps because glycine is also an important precursor of porphyrins inside and outside the chloroplast. The incorporation from $[1-14 \mathrm{C}]$ glyoxylate or $\left[1-{ }^{14} \mathrm{C}\right]$ glycine is of the order expected from the fixation of ${ }^{14} \mathrm{CO}_{2}$ liberated from these substrates during photorespiration. Confirmatory evidence comes from the work of Moss $(1966,1968)$, who has shown that the carbon dioxide evolved in photorespiration by leaves supplied with glycollate can be accounted for by photorespiration of the glycollate and can be inhibited by $\alpha$-hydroxypyrid-2-ylmethanesulphonate, an inhibitor of the glycollate-glyoxylate conversion. It would appear from the experiments with [1-14 $\mathrm{C}$ ]glycine and $\left[1{ }^{14} \mathrm{C}\right]$ malonate that total radioactivity incorporated into sterol is somewhat greater than into $\beta$-carotene. The reason for this observation is not clear though possibly the incorporation of radioactivity into sterol reflects metabolic conversion outside the chloroplast of the added compound into some metabolite, such as pyruvate or acetate, able to take part in extrachloroplastidic terpenoid biosynthesis.

The effective incorporation of $\left[{ }^{14} \mathrm{C}\right]$ formate into $\beta$-carotene is compatible with the involvement of the glycine $\rightarrow$ serine pathway. It is unlikely that the incorporation of radioactivity from [ $\left.{ }^{14} \mathrm{C}\right]$ formate into $\beta$-carotene is via formation of ${ }^{14} \mathrm{CO}_{2}$ because administering unlabelled glycine in the presence of [14 C]formate or administering unlabelled formate in the presence of $\left[2-{ }^{14} \mathrm{C}\right]$ glycine (see. Table 2) results, in each case, in a significant increase of radioactivity in $\beta$-carotene. If the observed incorporation of radioactivity from [ $\left.{ }^{14} \mathrm{C}\right]$ formate was 

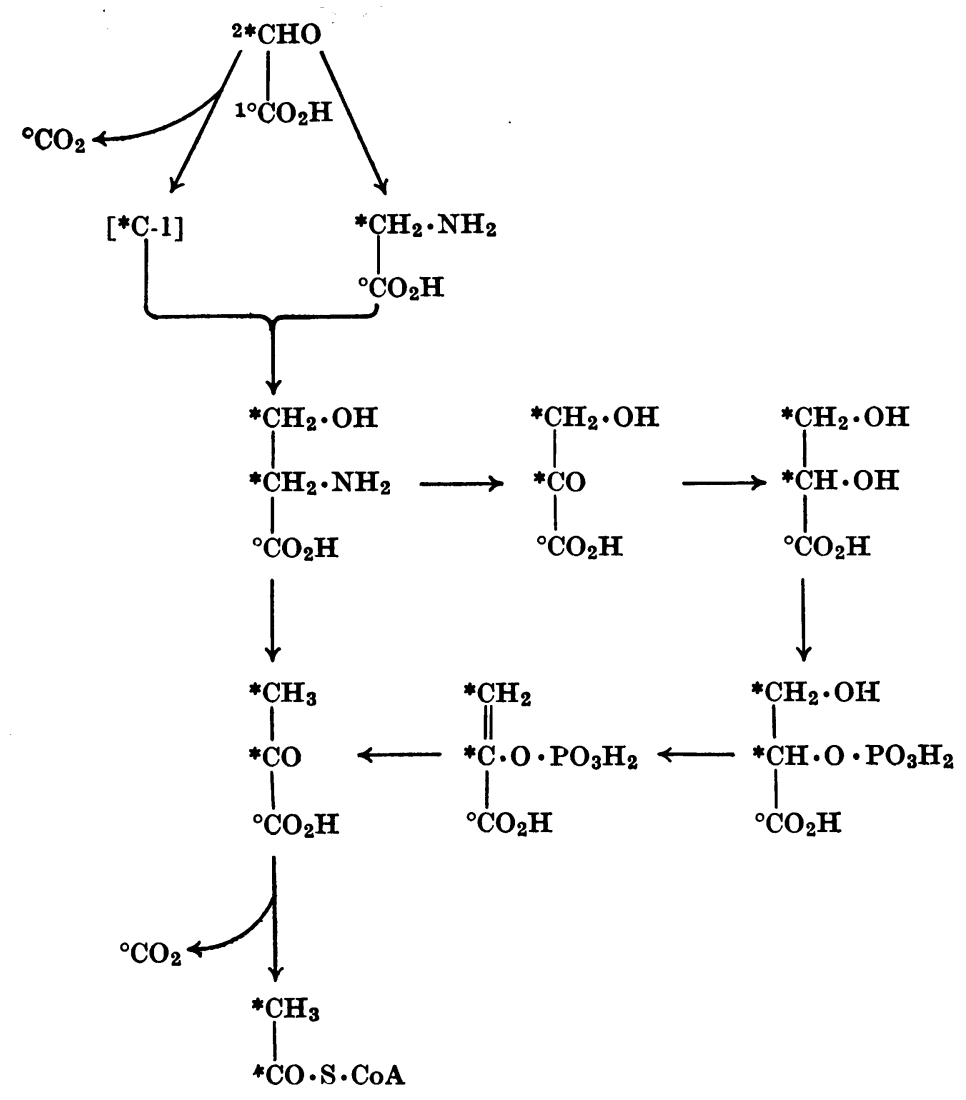

Scheme 3. Incorporation of C-2 of glyoxylate into acetyl-CoA via glycine and serine.

via ${ }^{14} \mathrm{CO}_{2}$ then administration in the presence of unlabelled glycine would result in an isotopedilution effect, and administration of unlabelled formate in the presence of [2.14C]glycine would not be expected to affect the incorporation of radioactivity into $\beta$-carotene. The activity in the sterols is probably due to the labelling of the methyl group of methionine, which is the precursor of the C-24 alkyl side chain of the phytosterols.

A later series of experiments (R. B. Evans \& L. J. Rogers, unpublished work) has shown that incorporation of serine into chloroplast terpenoids is via reversible cleavage to glycine since incorporation of radioactivity from [3-14 C]serine into chloroplast terpenoids was negligible in contrast with incorporation of radioactivity from [U-14C]serine. Significant incorporation of radioactivity could only be obtained if the $\left[3 .{ }^{14} \mathrm{C}\right]$ serine was supplied in the presence of isonicotinyl hydrazide to inhibit the serine-glycine interconversion or in the presence of large amounts of glycine and formate. The observed cleavage of the C-1 unit from serine is probably extrachloroplastidic. The latter observation emphasizes the care necessary in interpretation of data from isotope-incorporation experiments.

When we consider the incorporation of pyruvate into terpenoids in 'greening' maize we find that it is effectively incorporated into both $\beta$-carotene and sterols. Since this implies that the chloroplast membrane is permeable to pyruvate we should, from involvement of pyruvate in the proposed chloroplastidic glyoxylate to acetyl-CoA pathway, expect sterols outside the chloroplast to be labelled after administration of [2-14C]glyoxylate or $\mathrm{L}$ [U.14C]serine to seedlings. Possibly the limited incorporations observed can be explained on such a basis, though in vivo it is likely that most if not all of the pyruvate formed in the chloroplast is channelled into production of acetyl-CoA for synthesis of chloroplast components. Alternatively these data could be explained by a unidirectional permeability of the chloroplast membranes to pyruvate, 
i.e. although pyruvate can readily enter the chloroplast it cannot normally pass from the chloroplast to extrachloroplastidic sites.

On presentation of malonic acid to the seedlings it was observed that the incorporation of radioactivity from $\left[2-{ }^{14} \mathrm{C}\right]$ malonic acid into $\beta$-carotene and sterol was substantially greater than from [1-14C]malonate. It is known from studies of fatty acid synthesis in intact isolated chloroplasts that malonate, malonyl-CoA and acetyl-CoA penetrate the chloroplast membranes only with difficulty (Stumpf et al. 1967), whereas acetate enters readily. Inside the chloroplast acetate can be converted into acetyl-CoA and intact lettuce chloroplasts readily form long-chain fatty acids if supplied with acetate and appropriate cofactors (Burton \& Stumpf, 1966).

One might attempt to explain the incorporation of radioactivity from $[2-14 \mathrm{C}]$ malonic acid into $\beta$-carotene by the suggestion that the incorporation occurs through conversion into acetate, which, being able to enter the chloroplast, can then be used for terpenoid biosynthesis. This view is compatible with the greater incorporation of C-2 of malonic acid than of C-1.

It is therefore surprising to find that $[2-14 \mathrm{C}]$ acetate, though an excellent precursor of sterols, is but poorly incorporated into $\beta$-carotene in higher plants (Table 1). A similar situation occurs in Euglena (Cooper \& Benedict, 1967), where acetate is incorporated into $\beta$-carotene only after considerable randomization.

However, in crude plastid preparations of tomato and carrot root (Braithwaite \& Goodwin, 1960a,c) and in organisms such as the fungus Phycomyces blakesleeanus, where chloroplasts are absent but $\beta$-carotene is nevertheless synthesized (Braithwaite \& Goodwin, 1960b), both acetate and mevalonic acid are good precursors of carotenoids. These observations indicate that though acetate can readily enter the chloroplast it is only significantly utilized for terpenoid biosynthesis by senescing plastids. It may be that in young and maturing chloroplasts acetate is preferentially used for fatty acid synthesis. Alternatively it is possible that terpenoid biosynthesis may be 'intercompartmented' within chloroplasts in sites not accessible to acetate until senescence occurs. Raymundo, Griffiths \& Simpson (1967) have obtained evidence which they interpret as suggesting that two distinct sites of carotenoid synthesis occur within tomato chromoplasts, organelles morphologically derived from senescing chloroplasts. The observed incorporation of $\left[2{ }^{14} \mathrm{C}\right]$ malonate into $\beta$-carotene presumably proceeds by a route other than via decarboxylation to acetate, a similar conclusion to that reached by Higgins \& Kekwick (1969) from investigations on squalene synthesis in baker's yeast. Malonyl-CoA has been suggested as a 
possible intermediate in the synthesis of mevalonic acid from acetyl-CoA in Hevea latex (Weeks \& Kekwick, 1965), and in pigeon liver (Brodie, Wasson \& Porter, 1964). An enzyme catalysing conversion of malonate into its CoA derivative has been detected in chloroplasts (Barron, Squires \& Stumpf, 1961).

The suggested involvement of a glycollate $\rightarrow$ glyoxylate $\rightarrow$ glycin $\theta \rightarrow$ serine $\rightarrow$ pyruvate pathway in the formation of chloroplastidic terpenoids is also supported by isotope-dilution studies (Table 2). In all cases the isotope-incorporation studies gave results compatible with the proposed pathway and in accord with previous isotope-incorporation studies. Thus the incorporation of label from [2-14C]glycollate into $\beta$-carotene was markedly decreased in the presence of unlabelled glycine or L-serine. Both $\mathbf{L}$-serine and glycine decreased incorporation of radioactivity from [2-14C]glyoxylate into $\beta$-carotene by $75-80 \%$, and pyruvate decreased its incorporation almost completely. Similarly, L-serine almost totally suppressed incorporation of radioactivity from [2-14 C]glycine into $\beta$-carotene.

In contrast, addition of $\mathbf{L}$-serine did not significantly suppress incorporation of radioactivity from either $\left[2 .{ }^{14} \mathrm{C}\right]$ glyoxylate or $\left[2 .{ }^{14} \mathrm{C}\right]$ glycine into sterols, nor did the presence of glycine affect the labelling of sterols when [2-14C]glyoxylate was administered. However, the presence of pyruvate suppressed incorporation of radioactivity from [2-14C]glyoxylate into sterol by about $70 \%$.

The view that the biosynthetic route from glycollate is localized within the chloroplast is supported by the observation that mevalonic acid (to which the chloroplast membrane is comparatively impermeable), when added together with [2.14 C]glyoxylate, did not affect the incorporation of radio- activity from the latter into $\beta$-carotene though it decreased even further the already low incorporation into sterols. [2-14 C]Mevalonic acid supplied together with [2-14 C]glyoxylate gave labelling of $\beta$-carotene and sterols equivalent to the sum of the individual incorporations. The results thus indicate that extraplastidic terpenoids are not formed in significant amounts from glyoxylate via glycine and serine and that this particular biosynthetic route is confined within the chloroplast. Involvement of the route postulated is supported by the observation (R. B. Evans \& L. J. Rogers, unpublished work) that whereas glyoxylate substantially decreased incorporation of ${ }^{14} \mathrm{CO}_{2}$ into $\beta$-carotene glyceric acid has little effect.

Isotope-incorporation studies in the presence of inhibitors of the glycollate-to-serine pathway suggest the quantitative importance of this route in biosynthesis of chloroplast terpenoids (Tables 3 and 4). The two inhibitors used were $\alpha$-hydroxypyrid-2-ylmethanesulphonate, which inhibits glycollate oxidase (Zelitch, 1959; Zelitch \& Walker, 1964; Tolbert \& Hess, 1966) and isonicotinyl hydrazide, which inhibits the conversion of glycine into serine (Davison, 1956; Asada et al. 1965; Miflin \& Whittingham, 1966).

In preliminary studies it was found that over a $24 \mathrm{hr}$. period a concentration of $0.015 \mathrm{M}$ inhibitor lowered the synthesis of chlorophyll and $\beta$-carotene in illuminated etiolated maize seedlings by about $50 \%$.

In the isotope-incorporation studies about $20 \mathrm{~g}$. of excised etiolated maize seedlings was immersed in $0.015 \mathrm{M}$ inhibitor for $60 \mathrm{~min}$. The shoots were then transferred to a small beaker containing $10 \mu \mathrm{C}$ of the appropriate radioisotope in $0.015 \mathrm{M}$ inhibitor and illuminated for a further $23 \mathrm{hr}$. The $\beta$-carotene and sterol fractions were then extracted

Table 3. Effect of $\alpha$-hydroxypyrid-2-ylmethanesulphonate and isonicotinyl hydrazide on incorporation of ${ }^{14} \mathrm{CO}_{2}$ into terpenoids of illuminated etiolated maize seedlings

After two of the three groups of excised seedlings $(20 \mathrm{~g}$. each) had been standing in $0.015 \mathrm{M}$ inhibitor for $1 \mathrm{hr}$. all three were simultaneously exposed during the succeeding $23 \mathrm{hr}$. illumination, two still in the presence of inhibitors, to $60 \mu \mathrm{c}$ of ${ }^{14} \mathrm{CO}_{2}$.

Incorporation of ${ }^{14} \mathrm{CO}_{2}$

\begin{tabular}{|c|c|c|c|}
\hline \multirow[b]{2}{*}{ Conditions } & \multicolumn{3}{|c|}{ Incorporation or ${ }^{2} \mathrm{CU}_{2}$} \\
\hline & & $\begin{array}{c}0.015 \mathrm{M}-\alpha-\mathrm{Hydroxy}- \\
\text { pyrid-2-ylmethane } \\
\text { sulphonate }\end{array}$ & $\begin{array}{c}0.015 \text { M-Isonicotinyl } \\
\text { hydrazide }\end{array}$ \\
\hline $\begin{array}{l}\text { Unsaponifiable lipid (mg.) } \\
\text { Unsaponifiable lipid (d.p.m.) } \\
\beta \text {-Carotene ( } \mu \text { g.) } \\
\beta \text {-Carotene (d.p.m./mg.) } \\
\text { Sterol ( } \mu \text { g.) } \\
\text { Sterol (d.p.m./mg.) }\end{array}$ & $\begin{array}{r}91 \\
1026000 \\
106 \\
172000 \\
2100 \\
4860\end{array}$ & $\begin{array}{r}62 \\
52400 \\
52 \\
4000 \\
1600 \\
7230\end{array}$ & $\begin{array}{r}78 \\
72000 \\
56 \\
5500^{*} \\
1760 \\
6300\end{array}$ \\
\hline
\end{tabular}

* $\beta$-Carotene lost during attempted recrystallization. 
Table 4. Effect of $\alpha$-hydroxypyrid-2-ylmethanesulphonate on the incorporation of $\left[2 \cdot{ }^{14} \mathrm{C}\right] g l y c o l l a t e$ and $[2-14 \mathrm{C}]$ glyoxylate into terpenoids of illuminated etiolated maize seedlings

After standing in 0.015 M- $\alpha$-hydroxypyrid-2-ylmethanesulphonate for $1 \mathrm{hr}$. excised seedlings were exposed during the succeeding $23 \mathrm{hr}$. illumination, while still in the presence of inhibitor, to $10 \mu \mathrm{c}$ of substrate. For convenience comparable data for $[2-14 \mathrm{C}]$ glycollate and $[2-14 \mathrm{C}]$ glyoxylate are included from Table 1.

$\begin{array}{lrrrrr} & \overbrace{\begin{array}{c}\text { Without } \\ \text { inhibitor }\end{array}}^{\text {Substrate }} & \begin{array}{c}\text { With } \\ \text { inhibitor }\end{array} & \overbrace{\begin{array}{c}\text { Without } \\ \text { inhibitor }\end{array}}^{[2-14 \mathrm{C}] \text { Glycollate }} & \begin{array}{c}\text { With } \\ \text { inhibitor }\end{array} \\ \text { Wt. of seedlings (g.) } & 20 & 20 & 12 & 20 \\ \text { Unsaponifiable lipid (mg.) } & 88 & 48 & 42 & 81 \\ \text { Unsaponifiable lipid (d.p.m.) } & 249000 & 21200 & 462000 & 405000 \\ \beta \text {-Carotene ( } \mu \text { g.) } & 96 & 12 & 98 & 89 \\ \beta \text {-Carotene (d.p.m./mg.) } & 148000 & 1400 & 81900 & 80000 \\ \text { Sterol ( } \mu \text { g.) } & 1960 & 1720 & 800 & 1300 \\ \text { Sterol (d.p.m./mg.) } & 4200 & 6900 & 26600 & 14300\end{array}$

Table 5. Effect of isonicotinyl hydrazide on the incorporation of $\left[2-{ }^{14} \mathrm{C}\right]$ glyoxylate, $\left[2-{ }^{14} \mathrm{C}\right]$ glycine, $\left[{ }^{14} \mathrm{C}\right]$ formic acid and $\mathrm{L}-\left[\mathrm{U}-{ }^{14} \mathrm{C}\right]$ serine into terpenoids of illuminated etiolated maize seedlings

After standing in $0.015 \mathrm{M}$-isonicotinyl hydrazide for $1 \mathrm{hr}$. excised seedlings $(20 \mathrm{~g}$.) were exposed during the succeeding $23 \mathrm{hr}$. illumination, while still in the presence of inhibitor, to $10 \mu \mathrm{c}$ of substrate.

\begin{tabular}{|c|c|c|c|c|}
\hline Substrate & $\begin{array}{c}{[2-14 \mathrm{C}] \text { Glyoxylate }} \\
\text { + inhibitor }\end{array}$ & $\begin{array}{c}{[2-14 \mathrm{C}] \text { Glycine }} \\
+ \text { inhibitor }\end{array}$ & $\begin{array}{c}{[\mathrm{U} .14 \mathrm{C}] \text { Serine }} \\
+ \text { +inhibitor }\end{array}$ & $\begin{array}{l}\mathrm{H}^{14} \mathrm{CO}_{2} \mathrm{H} \\
\text { + inhibitor }\end{array}$ \\
\hline Unsaponifiable lipid (mg.) & 69 & 72 & 66 & 62 \\
\hline Unsaponifiable lipid (d.p.m.) & 41850 & 42850 & 179000 & 64250 \\
\hline$\beta$-Carotene ( $\mu \mathrm{g})$. & 31 & 39 & 78 & 31 \\
\hline$\beta$-Carotene (d.p.m./mg.) & 1200 & 1500 & 88000 & 960 \\
\hline Sterol ( $\mu \mathrm{g})$. & 1120 & 910 & 1010 & 1600 \\
\hline Sterol (d.p.m./mg.) & 18800 & 21300 & 7100 & 8650 \\
\hline Sp. radioactivity of $\beta$-carotene & 81900 & 66500 & 81700 & 32000 \\
\hline
\end{tabular}

(d.p.m./mg.) in the absence

of inhibitor (from Table 1)

and assayed as described previously. In experiments with ${ }^{14} \mathrm{CO}_{2}$ both control and experimental incubations were made simultaneously.

In all cases the results were in agreement with the postulated route of synthesis. Thus both $\alpha$-hydroxypyrid-2-ylmethanesulphonate and isonicotinyl hydrazide reduced the incorporation of radioactivity from ${ }^{14} \mathrm{CO}_{2}$ into $\beta$-carotene (Table 3) whereas the incorporation of ${ }^{14} \mathrm{CO}_{2}$ into sterol was not affected. Similarly, $\alpha$-hydroxypyrid-2-ylmethanesulphonate suppressed incorporation of radioactivity from [2-14 C]glycollate into $\beta$-carotene (Table 4), whereas the incorporation of radioactivity from [2-14C]glyoxylate was not significantly affected.

Table 5 illustrates comparable data for isonicotinyl hydrazide. In this case it was found that isonicotinyl hydrazide suppressed incorporation of radioactivity from [2.14 C]glyoxylate, [2.14 C]glycine and $\left.{ }^{14} \mathrm{C}\right]$ formate into $\beta$-carotene whereas incorporation of radioactivity from [U. ${ }^{14} \mathrm{C}$ ]serine was not affected.
In all experiments with inhibitors, except in those cases where the block in metabolism was overcome by addition of an appropriate metabolite, a quantitative inhibition of $\beta$-carotene synthesis was observed. In contrast, the inhibitors appeared to have no significant affect on the amount of sterol isolated by standard procedures or on its radioactivity compared with controls where the inhibitors were absent.

Confirmation of the proposed scheme in isolated chloroplasts is currently being sought from enzymic studies. Few data on this point are available though Rabson et al. (1962) report that glycollate oxidase resides primarily in the cytoplasm. However, Z. Kasai \& K. Asada quoted by Zelitch, $1965 b$ ) report the presence of both glycollate oxidase and glyoxylate reductase in isolated chloroplasts and the presence of the former in chloroplasts is also claimed by Delavan \& Benson (1959) and Chan \& Bassham (1967). In contrast Thompson \& Whittingham (1968) failed to find significant glycollate oxidase activity associated 
with chloroplasts prepared by a variety of methods. The differing results appear to depend on the buffers used in chloroplast isolation.

One of the enzymes, glycollate oxidase, involved in the proposed pathway is present in glyoxysomes (peroxisomes), small subcellular particles that have been detected in tissues such as castor-bean endosperm where the glyoxylate cycle is particularly active (Breidenbach, Kahn, \& Beevers, 1968). The particles, though of similar size, are morphologically distinct from proplastids and their function appears to be the formation of succinate from acetyl-CoA. Though these particles may be present in chloroplast-containing tissues available evidence does not appear to implicate them in formation of acetyl-CoA for chloroplast terpenoid biosynthesis.

It must be emphasized that our studies to date have been confined to one higher plant, maize, and in particular to greening etiolated tissues. The situation in other photosynthetic organisms may be different. In certain algae, for example, no glycollate oxidase appears to be present (Hess \& Tolbert, 1966b, 1967; Hess, Tolbert \& Pike, 1967) though NADH-glyoxylate reductase and phosphoglycollate phosphatase are. The suggestion of these workers was that the glycollate secreted after ${ }^{14} \mathrm{CO}_{2}$ fixation by some algae was the end product of an incomplete glycollate pathway and that serine required for synthesis of protein was formed, via hydroxypyruvate, from phosphoglyceric acid produced during photosynthesis. Even in algae, though, the situation is not clear since Zelitch \& Day (1968), Lord \& Merrett (1968) and Downton \& Tregunna (1968) have all recently identified glycollate oxidase as a constitutive enzyme in a number of algae.

The phosphoglycerate $\rightarrow$ hydroxypyruvate $\rightarrow$ serine pathway also occurs in higher plants (Stafford, Magaldi \& Vennesland, 1954; Willis \& Sallach, 1963; Chang \& Tolbert, 1965; Cheung, Rosenblum \& Sallach, 1968) though here the general flow of carbon atoms during photosynthesis appears to be glycollate $\rightarrow$ serine $\rightarrow$ glycerate, leading to sugars in the light or to malate in the dark. Thus the serine formed in plants during ${ }^{14} \mathrm{CO}_{2}$ fixation is uniformly labelled (Zelitch, 1959) as is the glycollate, glyoxylate and glycine (Chang \& Tolbert, 1965). Serine can also be formed in higher plant tissues (Hanford \& Davies, 1958) from phosphoglycerate via phosphohydroxypyruvate and phosphoserine.

The glycollate pathway for acetyl-CoA formation may well be only significant in young rapidly developing seedlings. As the chloroplast matures to a chromoplast its metabolism may be correspondingly altered. This is indicated by an increased incorporation of mevalonic acid into $\beta$-carotene in tomato chromoplasts; in contrast the incorporation of intermediates of the glycollate pathway into chloroplast terpenoids becomes progressively less efficient as the chloroplast senesces (H. M. Hill, S. P. J. Shah \& L. J. Rogers, unpublished work).

The authors are indebted to Professor T. W. Goodwin for his guidance and advice during these studies. We are also indebted to colleagues mentioned in the text for permission to quote unpublished results.

\section{REFERENCES}

Arnon, D. I. (1949). Plant Physiol. $24,1$.

Asada, K., Saito, K., Kitoh, S. \& Kasai, Z. (1965). Plant \& Cell Physiol., Tokyo, 6, 47.

Barron, E. J., Squires, C. \& Stumpf, P. K. (1961). J. biol. Chem, 236, 2610.

Braithwaite, G. D. \& Goodwin, T. W. (1960a). Biochem.J. 76, 1.

Braithwaite, G. D. \& Goodwin, T. W. (1960b). Biochem.J. 76, 5 .

Braithwaite, G. D. \& Goodwin, T. W. (1960c). Biochem. J. 76, 194.

Breidenbach, R. W., Kahn, A. \& Beevers, H. (1968). Plant Physiol. 43, 705.

Brodie, J. D., Wasson, G. \& Porter, J. W. (1964). J. biol. Chem. 239, 1346.

Burton, D. \& Stumpf, P. K. (1966). Arch. Biochem. Biophys. $117,604$.

Chan, H. W. S. \& Bassham, J. A. (1967). Biochim. biophys. Acta, 141, 426.

Chang, W. H. \& Tolbert, N. E. (1965). Plant Physiol. 40, 1048.

Cheung, G. P., Rosenblum, I. Y. \& Sallach, H. J. (1968). Plant Physiol. 43, 1813.

Cooper, C. Z. \& Benedict, C. R. (1967). Plant Physiol. 42 (Suppl.), S44.

Cossins, E. A. \& Sinha, S. K. (1966). Biochem. J. 101, 542.

Davison, A. N. (1956). Biochim. biophys. Acta, 19, 131.

Delavan, L. A. \& Benson, A. A. (1959). Brookhaven Symp. Biol. 11, 259.

Downton, W. J. S. \& Tregunna, E. B. (1968). Plant Physiol. 43, 923.

Goodwin, T. W. (1955). In Modern Methods of Plant Analysis, vol. 3, p. 373. Ed. by Paech, K. E. \& Tracey, M. V. Heidelberg: Springer-Verlag.

Goodwin, T. W. (1958). Biochem.J. 70, 612.

Hanford, J. \& Davies, D. D. (1958). Nature, Lond., 182, 532.

Hauschild, H. H. (1959). Canad. J. Biochem. Physiol. 37, 887.

Hess, J. L. \& Tolbert, N. E. (1966a). Ber. dtsch. bot. Ges. 70, 371.

Hess, J. L. \& Tolbert, N. E. (1966b). J. biol. Chem. 241, 5705.

Hess, J. L. \& Tolbert, N. E. (1967). Plant Physiol. 41 (Suppl.), xxxix.

Hess, J. L. \& Tolbert, N. E. \& Pike, I. M. (1967). Planta, 74, 278.

Hiatt, A. J. (1965). Plant Physiol. 40, 184.

Higgins, M. J. P. \& Kekwick, R. G. O. (1969). Biochem. J. 118, 36P.

Iwai, K., Susuki, N. \& Mizoguchi, S. (1967). Plant \& Cell Physiol., Tokyo, 8, 307. 
Kay, R. E. \& Phinney, B. (1956). Plant Physiol. 81, 226.

Kearney, P. G. \& Tolbert, N. E. (1962). Arch. Biochem. Biophys. 88, 164.

Krupka, R. M. \& Towers, G. H. N. (1959). Canad. J. Bot. 37, 539.

Lord, M. J. \& Merrett, M. J. (1968). Biochim. biophys. Acta, $159,543$.

Mackinney, G., Chichester, C. O., Nakayama, T. \& Goodwin, T. W. (1955). Biochem. J. 60, xxxvii.

Mazelis, M. \& Liu, E. S. (1967). Plant Physiol. 42, 1763.

Miflin, B. J. \& Whittingham, C. P. (1966). Ann. Bot., Lond., N.S., 30, 339.

Moss, D. N. (1966). Plant Physiol. 41 (Suppl.), xxxviii.

Moss, D. N. (1968). Crop Sci. 8, 71.

Orth, G. M., Tolbert, N. E. \& Jiminez, E. (1966). Plant Physiol. 41, 143.

Prather, C. W. \& Sisler, E. C. (1966). Plant \& Cell Physiol., Tokyo, 7, 457.

Rabson, R., Tolbert, N. E. \& Kearney, P. C. (1962). Arch. Biochem. Biophys. 98, 154.

Raymundo, L. C., Griffiths, A. E. \& Simpson, K. L. (1967). Phytochemistry, 6, 1527.

Roberts, D. W. A. \& Perkins, H. J. (1966). Biochim. biophys. Acta, 127, 42.

Rogers, L. J., Shah, S. P. J. \& Goodwin, T. W. (1967). Abstr. 7th int. Congr. Biochem., Tokyo, vol. 4, E110.

Shah, S. P. J., Rogers, L. J. \& Goodwin, T. W. (1967a). Biochem. J. 103, 52 P.

Shah, S. P. J., Rogers, L. J. \& Goodwin, T. W. (1967b). Biochem.J. 105, 13 P.

Shah, S. P. J., Rogers, L. J. \& Goodwin, T. W. (1968). Biochem. J. 108, 7 P.

Shetty, A. S. \& Miller, G. W. (1966). Plant Physiol. 41, 415.
Sinha, S. K., \& Cossins, E. A. (1964). Biochem. J. 93, 27.

Sinha, S. K. \& Cossins, E. A. (1965). Biochem. J. 96, 254.

Smirnov, B. P. \& Rodionov, M. A. (1964). Biokhimiya, 29, 386.

Stafford, H. E., Magaldi, A. \& Vennesland, B. (1954). J. biol. Chem. 207, 621.

Stumpf, P. K., Brooks, J., Galliard, T., Hawke, J. C. \& Simoni, R. (1967). In Biochemistry of Chloroplasts, vol. 2, p. 213. Ed. by Goodwin, T. W. London: Academic Press (Inc.) Ltd.

Tanner, H. A., Brown, T. E., Eyster, H. C. \& Treharne, R. W. (1960). Biochem. biophys. Res. Commun. 3, 205.

Thompson, C. M. \& Whittingham, C. P. (1968). Biochim. biophys. Acta. 153, 260.

Tolbert, N. E. (1963). In Photosynthetic Mechanisms of Green Plants, p. 648. Washington: National Academy of Sciences-National Research Council.

Tolbert, N. E. \& Hess, J. L. (1966). J. biol. Chem. 241, 5712.

Treharne, K. J., Mercer, E. I. \& Goodwin, T. W. (1966). Biochem. J. 99, 239.

Wang, D. \& Waygood, E. R. (1962). Plant Physiol. 37, 826.

Weeks, G. \& Kekwick, R. G. O. (1965). Biochem. J. 96, 52 P.

Wieckowski, S. \& Goodwin, T. W. (1967). Biochem. J. 105, 89.

Wilkinson, A. P. \& Davies, D. D. (1958). Nature, Lond., 181, 1070.

Willis, J. E. \& Sallach, H. J. (1963). Phytochemistry, 2, 23. Zelitch, I. (1959). J. biol. Chem. 234, 3077.

Zelitch, I. (1964). Annu. Rev. Plant Physiol. 15, 121.

Zelitch, I. (1965a). J. biol. Chem. 240, 1869.

Zelitch, I. (1965b). Biol. Rev. 40, 463.

Zelitch, I. \& Day, P. R. (1968). Plant Physiol. 43, 289.

Zelitch, I. \& Walker, D. A. (1964). Plant.Physiol. 39, 856. 